\title{
Roadside-Golf-Course Natural Science
}

\section{(Cypress Hills Provincial Park, Saskatcheuan)}

\section{By H. C. Andrews, Prin. Normal School, Moose Jaw, Director S.N.H.S.}

We (Mrs. A. and writer) drove into Cypress Hills Provincial Park Sunday evening, August 3 rd. The lodge and cottages are situated around a beautiful little lake created by building a dam on a site originally selected by a company of beaver engineers.

In the woods that cover the low- lying hills surrounding the lake, lodge-pole pine and aspen popular predominate. The stand of lodge-pole pine in the Park is said to be one of the most extensive in North America. Immediately around the lake a good growth of spruce is gradually establishing itself.

Exercise, through the medium of golf, was a main reason for our going to the Park. So on Monday, not too early, we headed for the beautiful, challenging, nine-hole golf course. Roadsides along the way were albaze with color- purple fireweed, mauve berganot, blue asters and hare bells, yellow agoseries and golden rod, and

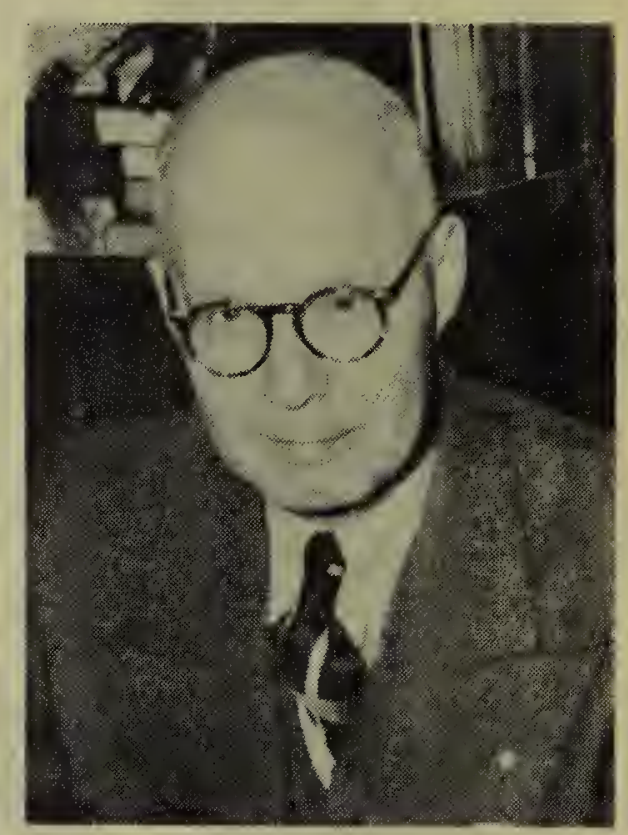
white yarrow and caraway vying with each other to add their measure of beauty. The golf course is situated back from the camp site where the woods begin to give way to more open country. Trees along some of the fairways cause plenty of trouble for many players. In open stretched boarding other fairways, and throughout the woods, millions of wild flowers display their beauty. The fairways, too, which had not recently mowed, were strewn with purple and white fleabane daisies, yellow agoseries, purple amny-flowered gentian, silvery pussy toes and others. It was almost like playing golf in a huge garden.

$N$ ature plants in a wide variety of arrangements. Here a mass of purple fireweed. There a patch of rosetinted paint brush. Across the way, white caraway. In places, all the color seemed to be present in a great planting of many varieties. Sometimes the colors of only two or three varieties were mixed together.

We soon found that wild flowers challenged and interested us almost as much as golf. One hike around the lake, one special trip to the golf course, one tramp back through the woods, and a bit of observing and collecting when out in the rough looking for golf balls, yielded a total of 59 identified wild flowers, nine wild fruits, and 10 weeds. We also found juniper, bearberry, dogwood, sheperdia and snowberry. In a quiet corner of the lake, were tiny, white

water crowfoot flowers. It was a treat, too, to find such plants as bunchberry, red and white baneberry, and fairy bells, in parts of the woods.

On one fairway, a view across several miles of country liberally dotted with bluffs - the darker green of the pine contrasting strikingly with the lighter color of the spruce presented a truly beautiful picture.

We kept our eyes open for birds and saw numorous juncoes, several chickadees and sharp-tailed grouse, one cedar waxwing, one red-breasted nuthatch, and one ruffed grouse. It was a great thrill for me one day to identify a lone western tanager. Another day, a single meadowlark streaked across a fairway in what $I$ would say was not typical meadowlark country. A flock of bluebirds "played golf" with us frequently. I have identified them as "mountains", but it is possible they were "westerns".

Once we surprised (or vica versa) a white-tail doe with twin fawns. We were advised that in the fall deer are plentiful in the Park. There are also elk. Another time we discovered fo ur beaver dams in succession, each dam some $25-30$ feet below the one above it. There were no signs of recent activities. I believe, beavers are not welcone "guests" in the Park. Richardson's ground squirrels were too common on several fairways. Two newly excavated 